\title{
A escolarização do corpo infantil: uma compreensão do discurso pedagógico a partir do século XVIII
}

\author{
Marynelma Camargo Garanhani* \\ Vera Luiza Moro**
}

\begin{abstract}
RESUMO
Dentre as possíveis concepções de corpo presentes na história da filosofia que influenciaram o pensamento educacional, o texto que se apresenta, centra esforços para discutir o momento em que o corpo passa a ser percebido em seus aspectos científico-biológico e psicológico, ao mesmo tempo em que ocorre o surgimento do processo de escolarização da infância e a incorporação da criança no universo dos estudos científicos. Justifica-se o estudo na medida que esta reflexão se faz necessária na formação de educadores, já que não se tem priorizado discussões em torno desta temática. Palavras-chave: corpo, escolarização e infância.
\end{abstract}

\begin{abstract}
Among several body conceptions which are presented in phylosophy history and which influenced by educational thinking, the present paper aims at discussing the moment at which the body started to be perceived in its scientific-biological and psychological aspects, at the same time that the process of school education in infancy started, and the child was introduced in the scientific studies. This study is important as this reflection is important to the educators' formation which hasn't given priority to discussions about that subject.
\end{abstract}

Key-words: body, schooling and infancy.

* Professora do Departamento de Educação Física da UFPR. Mestre em Educação pela UFPR e Doutoranda em Psicologia da Educação na PUC/SP.

** Professora do Departamento de Educação Física da UFPR. Licenciada em Educação Física e Mestre em Educação pela UFPR. 


\title{
Delineando um momento histórico...
}

Dentre as possíveis concepções de corpo presentes na história da filosofia ocidental que influenciaram o pensamento educacional, prevaleceram durante muito tempo, aquelas que se pautavam pela valorização do espírito, em detrimento do corpo, conforme nos atesta ASSMANN (1994, p. 73):

\begin{abstract}
O corpo jardim fechado (como rezam ladainhas cristãs: hortus conclusus). Predominou no Ocidente entre, pelo menos, 3000 a. C. até 1700 d. C., subsiste, cultivado, por muitos lados. Templo, morada, mistério inviolável, âmbito de deuses e demônios, Éden proibido e cobiçado, árvore da vida mas também do bem e do mal, corpo virgem, hóstia, vítima sacrificial, cadáver sagrado. Quantas excitações e quantos arrepios de espanto.
\end{abstract}

Não obstante a prevalência destas concepções de corpo e sua influência no pensamento educacional, este texto pretende discutir o momento em que o corpo passa a ser percebido em seus aspectos científico-biológico e psicológico, ao mesmo tempo em que ocorre o surgimento do processo de escolarização do corpo infantil e a incorporação da criança no universo dos estudos científicos.

Pode-se afirmar que com o advento do empirismo, e mais precisamente com o dualismo cartesiano, estabeleceu-se, segundo ABBAGNANO (1982, p. 197), "um ponto de vista que, antes de Descartes, não se apresentara nunca". Em relação ao fato, ABBAGNANO (1982, p. 197) faz ainda o seguinte comentário:

[...] crê-se comumente que a separação instituída por Descartes entre alma e corpo, como entre duas substâncias diferentes, tenha tido como consequiência o estabelecer a independência da alma em relação ao corpo. $\mathrm{Na}$ verdade, a sua primeira consequência foi a de estabelecer a independência do corpo em relação à alma e conclui: "Desse novo ponto de vista, o corpo aparece como uma máquina, uma máquina que caminha por si. (ABBAGNANO, 1982, p. 197)

Locke, em sua obra Pensamentos sobre Educação, passa a utilizar o termo físico e, para NEGRÃo (1999, p. 49), “A partir de Locke o termo físico passa a ter duas conotações no interior da escola: a primeira é o termo físico como phisis, estudo da natureza, e a segunda é o termo físico vinculado à vida física, o corpo, conforme a concepção de Descartes".

Resguardadas as profundas diferenças entre o Racionalismo idealista e o Empirismo, pode-se dizer que é sob a influência destas matrizes teóricas que 
se inicia um processo de afirmação do corpo em seu aspecto científicobiológico e psicológico, resultando em termos educacionais, em um movimento de recomendação e cuidados com o corpo na forma de exercícios físicos, de informações sobre a saúde e de cuidados com as crianças, no sentido de sua conservação.

Com relação a este aspecto da conservação das crianças, DONZELOT (1980, p. 15) afirma que, a partir do século XVIII, começa a florescer uma abundante literatura sobre o tema, produzida inicialmente por médicos e seguida por administradores, militares e filósofos preocupados tanto com o empobrecimento da nação, quanto com o enfraquecimento da elite.

\section{A ênfase na educação da infância e a escolarização do corpo infantil}

Com a intenção de provocar uma reflexão em torno da ênfase dada à educação da criança no século XVIII, de modo a compreender como se deu a escolarização do corpo infantil, este texto inicia com a lembrança de que é somente no século XVII que ocorre o desenvolvimento do sentimento de infância, passando a criança, neste momento, a existir como objeto de afeto e de conhecimento para a sociedade.

PINTO (1997), em seus estudos sobre a infância como construção social, endossa as afirmações anteriores ao dizer:

[...] a infância constitui uma realidade que começa a ganhar contornos a partir dos séculos XVI e XVII. [...] As mudanças de sensibilidade que se começam a verificar a partir do Renascimento tendem a diferir a integração no mundo adulto cada vez para mais tarde, e a marcar, com fronteiras bem definidas, o tempo da infância, progressivamente ligado ao conceito de aprendizagem e de escolarização. Importa, no entanto, sublinhar que se tratou de um movimento extremamente lento, inicialmente bastante circunscrito às classes mais abastadas. (PINTO, 1997, p. 44)

Com isto, ressalta-se que é exatamente no século XVIII que a imagem da infância mudou, devido à instalação de uma valorização e reorganização dos comportamentos educativos, desencadeando uma preocupação da sociedade em procurar novos métodos de educar e escolarizar as crianças.

LUZURIAGA (1987) relata que o século XVIII foi o século pedagógico 
por excelência, pois a educação passou a ocupar o primeiro plano na sociedade e duas das maiores figuras da pedagogia e da educação da infância, responsáveis por este cenário, foram Rousseau e seu discípulo Pestalozzi.

Rousseau, nessa época, combateu idéias que prevaleciam há muito tempo sobre a educação da criança, entre elas, a de que a teoria e a prática educacional, na infância, deveriam focalizar os interesses do adulto e da vida adulta. Desta maneira, chamou a atenção para as necessidades da criança em cada idade e as condições de seu desenvolvimento. Insistiu, portanto, em procurar conhecer, profundamente, as características da infância, para que a educação da criança pequena fosse melhor.

Para isto, publicou a obra Emílio, na qual apresentou uma proposta educacional incompatível com a situação vigente na época (havia degradação dos costumes, ausência de liberdade e crescimento da desigualdade). Rousseau, ao abordar em sua obra o corpo infantil, justificou a necessidade de uma educação física para a infância, invocando vários autores que são unâmines em confirmar a importância do exercício corporal na educação das crianças, entre eles estava Locke. (CERIZARA, 1990)

As aproximações existentes entre Locke e Rousseau, no que diz respeito à importância da educação corporal das crianças, a preocupação com as peculiaridades destas, e com um ensino que utilizasse recursos naturais, permitem lembrar que existem diferenças entre a conduta corporal proposta por Locke na educação do gentil-homem, e a conduta corporal do Emílio, proposta por Rousseau. Quanto às técnicas de corpo em Locke e Rousseau, SILVA (1998, p. 63) faz o seguinte comentário:

Para Rousseau a formação de Emílio passava, também, pela educação do corpo. Talvez por se basear em Locke, mesmo criticando-o pelo contexto social semelhante: precárias condições de higiene e alto índice de mortalidade infantil, Rousseau também sugeriu recomendações quanto à alimentação, vestuário e exercícios. No entanto, apesar das semelhanças, as justificativas teóricas para tais recomendações eram distintas. Pois, enquanto Locke estabelecia as prescrições corporais a partir dos conhecimentos médicos para atingir a saúde do homem de negócios, Rousseau era contrário às práticas médicas, pois elas 'aviltam a coragem do homem e o levam a desaprender de morrer', já que ele objetivava aproximar o homem do estado de natureza.

Rousseau, então, recomenda, na educação da infância, o exercício do corpo, dos órgãos e dos sentidos, entendendo-os como aspectos que desenvolvidos se transformarão em instrumentos para a criança construir o seu conhecimento. Ele descreve: "se quiser cultivar a inteligência de seu aluno, cultive as forças que ela deve governar. Faça-o exercer continuamente seu 
corpo; torne-o robusto e sadio para torná-lo sábio e sensato: que ele trabalhe, aja, corra, grite, esteja sempre em movimento; que seja homem pelo vigor, e logo o será pela razão" (ROUSSEAU, apud CERIZARA, 1990, p. 134) e complementa dizendo: "a verdadeira razão do homem não se desenvolve independentemente do corpo; é a boa constituição deste que torna as operações do espírito fáceis e certas" (ROUSSEAU, apud CERIZARA, 1990, p. 141). Portanto, para Rousseau, o entendimento humano passa pelos sentidos, sendo a primeira razão do homem, a razão sensitiva, suporte da razão intelectual.

Observa-se também em Rousseau, uma preocupação com a educação física da criança durante a sua infância, mas em sua escolarização, esta se faz como condição para o desenvolvimento da razão.

Pestalozzi, seguindo Rousseau, também preocupou-se com a educação da criança, dedicando sua vida a esta causa. Defendia as idéias de que a criança começa a sua aprendizagem desde o nascimento, ou seja, que a infância não era um mero período latente, de esperar para ficar adulto, e, mediante isto, justifica a necessidade de pensar uma educação infantil que leve em conta o desenvolvimento psíquico da criança.

Preocupado com uma educação moral desde a infância, Pestalozzi enfatiza a necessidade da interação de uma formação intelectual, moral e física na educação da criança e, segundo INCONTRI (1997), sua pedagogia está toda voltada para ação. Com isto, a formação corporal ocupa um lugar de destaque em seu método, pois Pestalozzi propõe a percepção, por meio da ação, como base de toda a educação. Para Pestalozzi, a percepção, no processo educacional, está em primeiro lugar, pois defende que a apreensão inicial da realidade não ocorre pela palavra, ou seja, o conteúdo deverá preceder a linguagem. A partir desta tese, Pestalozzi desenvolve uma proposta de ensino que parte do concreto para o abstrato, utilizando-se do material concreto para provocar na criança o sentir objetos, ao invés de ouvir falar deles.

Diante de tais fatos, observa-se que Pestalozzi reforça as idéias de Rousseau em torno de uma educação física na infância como condição para o desenvolvimento da razão, não superando o dualismo corpo-mente que vigorava, até então, no pensamento pedagógico.

Embora Pestalozzi priorizasse a educação no lar, dada pela mãe, foi ele um dos responsáveis pela institucionalização da educação na infância, durante o século XVIII, defendendo a formação de professores, como peças fundamentais na educação. Neste contexto de idéias, surgem, então, as escolas obrigatórias para crianças entre cinco e treze anos, como também escolas para a preparação de mestres, com a condição de que ninguém poderia ensinar as crianças sem ter o título correspondente. Mas o fortalecimento da instituição escolar para crianças ocorre somente no século XIX, conforme a descrição de 
LUZURIAGA (1987, p. 180):

[...] do século XIX procedem os sistemas nacionais de educação e as grandes leis da instrução pública de todos os países europeus e americanos. Todos levam a escola primária aos últimos confins de seus territórios, fazendo-a universal, gratuita, obrigatória e, na maior parte leiga ou extraconfessional. Pode-se dizer que a educação pública, no grau elementar, fica firmemente estabelecida, com o acréscimo de dois novos elementos: as escolas da primeira infância e as escolas normais para a preparação do magistério.

Como conseqüência, as instituições pré-escolares se firmam nos países europeus e americanos como jardins de infância, não apenas devido às profundas transformações que a sociedade enfrentou, mas também à influência de descobertas da psicologia e da pedagogia, no que se refere ao processo de desenvolvimento e aprendizagem infantil.

Segundo NICOLAU (1997), foi Froebel, discípulo de Pestalozzi, que, em pleno surgimento da Revolução Industrial, criou na Alemanha em 1837, o primeiro Jardim de Infância - Kindengarten -, dedicando o restante de sua vida à fundação de Jardins de Infância, à formação de professores e à elaboração de métodos e equipamentos para tais instituições escolares.

NICOLAU (1997) ainda afirma, em seus estudos, que Froebel foi o primeiro educador a sistematizar orientações metodológicas sobre o brinquedo, o jogo e o desenho na educação escolar infantil. Seguindo as idéias de Pestalozzi, este entendia a educação como uma atividade que se desenvolve num contínuo diálogo entre pensamento e ação (KOCH, 1985) e, por isto, propõe a utilização didático-pedagógica do brinquedo e do jogo. ROLLA e ROLLA (1994) descrevem, em seus estudos, que Froebel, sensibilizado pelos jogos infantis, percebe as vantagens intelectuais e morais destes e, para além do desenvolvimento físico e defendendo a liberdade da criança, utiliza a tendência lúdico-espontânea para uma educação integral na infância.

Nesse contexto, observa-se que Froebel foi o precursor ao desencadear uma sistematização pedagógica de atividades que envolvessem a movimentação do corpo na escolarização da infância, por meio da introdução do brinquedo e do jogo infantil. Mas é interessante ressaltar que o objetivo desta sistematização pedagógica ainda se dá como condição para o desenvolvimento da razão intelectual na infância, reforçando, portanto, no século XIX, uma preocupação em escolarizar o corpo infantil, como favorecimento à educação do pensamento da criança.

No final do século XIX e início do século XX, ocorreu em várias regiões da Europa, uma expansão de experiências pedagógicas inovadoras para a educação da infância e, entre elas, ressalta-se dois sistemas de grande difusão: na 
Itália, o Método Montessoriano, criado por Maria Montessori e, na Bélgica, as propostas pedagógicas de Decroly. Ambos nasceram da observação de crianças deficientes e foram sistematizados por educadores com formação em medicina. Assim, nessa época, ocorreu uma valorização em torno de observações de crianças com crescimento e desenvolvimento irregular ou anormal, para que se pudesse esclarecer o que se admitia por desenvolvimento regular, ocorrendo, com isto, sistematizações científicas das diferentes fases e períodos do desenvolvimento infantil. Portanto, este contexto científico justifica, a influência dos conhecimentos biológicos e psicológicos na formulação das bases técnicas de uma nova educação infantil que se apresentava.

Maria Montessori enfatizava em seu método de educação o aspecto biológico do crescimento e desenvolvimento infantil, descrevendo que a vida era desenvolvimento e educar era permitir esse desenvolvimento. Sua escola tinha como princípio a liberdade, ressaltando que esta liberdade não significava abandono e sim permitir o desenvolvimento das manifestações espontâneas da criança, identificando-a como atividade. Para isto, propôs a transformação do ambiente escolar e o respeito à individualidade.

Montessori revolucionou a concepção de sala de aula para crianças pequenas através da organização e montagem do ambiente escolar, quando, ao reduzir o tamanho do mobiliário escolar, este tornou-se mais adequado ao tamanho do corpo infantil. Criou também materiais adequados à exploração sensorial, conforme o objetivo educacional a ser trabalhado, e justificativa que as sensações eram as bases das funções intelectivas. (NICOLAU, 1997)

Já Decroly, apresentava em seu método de educação os seguintes princípios fundamentais: o da globalização e o do interesse. Pelo princípio da globalização, defendia o pensamento da criança como não sendo analítico, mas sintético, isto é, a criança entende o todo e não as partes; e em relação ao interesse da criança, defendia que este nasce da necessidade e, com isto, propôs organizar o ensino escolar por centros de interesse. (ROLLA; ROLLA, 1994)

Entendendo que o fim último da educação é o desenvolvimento e a conservação da vida, Decroly descreve que a educação deveria colocar o indivíduo, com a maior economia de energia e de tempo, em condições de alcançar o grau de desenvolvimento que a sua constituição e solicitações do meio lhe exigem. Para isto, defendia que o máximo rendimento do ensino escolar exige prévia classificação dos alunos, baseada na estatística e no exame físico e psíquico de cada criança. (ROLLA; ROLLA, 1994)

Sob este ponto de vista, observa-se, que enquanto Montessori, na educação da infância, dedicava atenção à educação sensorial; Decroly apostava preferencialmente na educação intelectual (ROLLA; ROLLA, 1994), mas ambos 
propunham a escolarização do corpo da criança, como forma de expressão que permite a manifestação e o desenvolvimento do pensamento na infância.

É importante observar que neste contexto histórico, existiram outras experiências e propostas pedagógicas importantes na educação da infância, mas estas não serão aqui abordadas devido às limitações de espaço e tempo que um texto acadêmico impõe à descrições e reflexões sobre contextos históricos. Optou-se neste estudo pelas propostas educacionais de Montessori e Decroly devido à forma como estes estudiosos abordaram a escolarização da criança e conseqüentemente o seu corpo, retratatando, portanto, os aspectos científicobiológico e psicológico presentes na educação escolar infantil dessa época.

Em síntese, SCHMIDT (1997) descreve que os séculos XVII e XVIII, foram os séculos da descoberta da infância e o século XIX o momento fundante da produção de saberes na tentativa de explicá-la, mas foi realmente no século XX que ocorreu um intenso movimento internacional em favor da criança, do seu estudo e da sua educação, sendo, portanto, denominado o século da criança.

Após a Primeira Guerra Mundial, no século XX, houve um momento significativo de debates e discussões em torno do cuidado, preservação e preparação da infância. Mas foi somente após a Segunda Guerra Mundial que ocorreu um movimento de valorização e expansão do atendimento escolar à criança pequena, que assumiu um caráter de assistência social devido ao trabalho feminino. Segundo KRAMER (1987), esse movimento despertou o interesse de novas formas de atuação com as crianças, as quais passaram a vivenciar situações antes desconhecidas, como a ausência do pai (convocado para a guerra) e, muitas vezes, a da mãe (engajada no trabalho produtivo). Assim, surgiu, na educação da infância, uma preocupação com as necessidades emocionais e sociais das crianças.

Como conseqüências, nessa época, houve uma grande influência da teoria psicanalítica e das teorias do desenvolvimento infantil nas orientações metodológicas para a educação escolar da infância, conforme revela KRAMER (1987, p. 28):

[...] a psicanálise fortalecia as intensas discussões existentes em torno da maior ou menor permissividade que deveria existir na educação das crianças, trazendo à discussão temas tais como frustração, agressão, ansiedade. A atenção de professores se voltava para as necessidades afetivas da criança e para o papel que o professor deveria assumir, dos pontos de vista clínico e educacional. Concomitantemente, sendo difícil determinar se como causa ou consequiência do ressurgimento da educação pré-escolar, houve a redescoberta, durante os anos 50, dos trabalhos teóricos de Montessori, Piaget e Vigotsky. Crescia concomitantemente o interesse de estudiosos da aprendizagem pelo conhecimento dos aspec- 
tos cognitivos do desenvolvimento, pela evolução da linguagem, e pela interferência dos primeiros anos de vida da criança no seu desempenho acadêmico posterior. A preocupação com os métodos de ensino reapareceria.

Considera-se que as transformações profundas na escolarização da infância ocorreram nos anos 60, desencadeadas segundo KRAMER (1987) e SPODEK e BROWN (1996), por uma série de fatores sociais, políticos, econômicos e ideológicos, sendo um deles, o interesse renovado da comunidade científica sobre o papel do meio no desenvolvimento humano. Nessa época, as pesquisas que tinham como tema a educação infantil, estavam centradas nos estudos do pensamento da criança e da influência da linguagem no rendimento escolar.

Em decorrência destes fatos, os anos 70 constituíram-se nos anos pródigos em currículos e programas educativos para a criança e desencadearam, nos anos posteriores, pesquisas sobre as formas de fazer e de pensar a educação da pequena infância. ROCHA (1999a/b), em suas recentes pesquisas sobre o estado do conhecimento da educação infantil no Brasil, confirma este desencadeamento de investigações sobre a educação da criança ao relatar que o conhecimento científico da pequena infância e sua educação aflorou de forma significativa nos últimos trinta anos. Ao descrever as tendências da pesquisa em educação infantil, no âmbito mundial, diz que estas centralizam-se em torno das relações educativas, estabelecidas junto à criança pequena, num espaço institucional, cuja função precípua é a educação e o cuidado como elementos indissociáveis.

Mas como se apresenta a escolarização do corpo infantil na educação da infância do século XX? Como as propostas educacionais do século XX, denominado o século da criança, compreendem a educação e escolarização do corpo infantil? Quais são os estudos sobre a educação da infância para o século XXI, que abordam uma discussão sobre o corpo infantil nas instituições escolares? Estas indagações mobilizam novos estudos e reflexões em torno da compreensão do corpo infantil nas políticas educacionais contemporâneas para a educação da infância, revelando, assim, a necessidade de estudos que analisem o discurso pedagógico sobre a escolarização da infância no século XX e, conseqüentemente, as propostas que estão emergindo para o século XXI. 


\section{Ensaiando conclusões...}

Pelas reflexões realizadas no estudo, observou-se que a educação e a escolarização da infância, historicamente, vêm sendo pautadas por um modelo de racionalidade sobre o significado do corpo e seu movimentar, como condição para o desenvolvimento da razão intelectual. Esta racionalidade no pensamento, explícita no discurso pedagógico a partir do século XVIII, constituiu-se, nestes últimos séculos, a matriz teórica da educação escolar infantil.

Repensar atualmente o corpo, na educação e escolarização da infância, exigiria uma mudança na lógica do pensamento educacional, presente desde o século XVIII, mas, para isto, é necessário uma especial atenção à formação de educadores.

Assim, conhecimentos e discussões que priorizem a educação do corpo na escolarização da infância devem estar presentes na formação dos educadores, proporcionando-lhes condições de compreender a expressividade, as emoções, os gestos, os movimentos, ou seja, os significados do corpo infantil.

\section{REFERÊNCIAS}

ABBAGNANO, Nicola. Dicionário de filosofia. São Paulo: Mestre Jou, 1982.

ASSMANN, Hugo. Paradigmas educacionais e corporeidade. 2. ed. Piracicaba: Unimep, 1994.

CERIZARA, Beatriz. Rousseau. A educação na infância. São Paulo: Scipione, 1990.

DONZELOT, Jacques. A polícia das famílias. Rio de Janeiro: Graal, 1980.

INCONTRI, Dora. Pestalozzi. Educação e ética. São Paulo: Scipione, 1997.

KOCH, Dorvalino. Desafios da educação infantil. São Paulo: Loyola, 1985.

KRAMER, Sonia. A Política do pré-escolar no Brasil: a arte do disfarce. 3. ed. Rio de Janeiro: Dois Pontos, 1987.

LUZURIAGA, Lorenzo. História da educação e da pedagogia. São Paulo: Nacional, 1987. 
NEGRÃO, Ronaldo Ferreira. Educação Física: a educação da "físicalidade" humana. São Paulo, 1999. Dissertação (Mestrado em Psicologia da Educação) - Pontifícia Universidade Católica de São Paulo.

NICOLAU, Marieta Lúcia Machado. A educação pré-escolar. Fundamentos e Didática. 9. ed. São Paulo: Ática, 1997.

PINTO, Manuel. A infância como construção social. In: PINTO, Manuel; SARMENTO, Manuel Jacinto. As crianças - contextos e identidades. Braga: Centro de Estudos da Criança/Universidade do Minho - Portugal, 1997.

ROCHA, Eloisa Acires Candal. A pesquisa em educação infantil no Brasil: uma trajetória recente e perspectivas de consolidação de uma pedagogia. Florianópolis: UFSC, 1999a.

. A pesquisa sobre educação infantil: trajetórias e perspectivas. Perspectiva, $\mathrm{Re}-$ vista do Centro de Ciências da Educação, Florianópolis, v.17, n. especial, p. 61-71, $1999 b$.

ROLLA, Anabela; ROLLA, Jorge Silva. O projecto educativo em educação de infância. Lisboa: ASA, 1994.

SCHIMIDT, Maria Auxiliadora Moreira dos. Infância: sol do mundo. A primeira Conferência Nacional de Educação e a construção da infância brasileira. Curitiba, 1927. Curitiba, 1997. Tese (Doutorado em História) - Universidade Federal do Paraná.

SILVA, Pierre Normando Gomes. A cultura corporal burguesa: seu contexto histórico e suas primeiras sistematizações pedagógicas. João Pessoa, 1998. Dissertação (Mestrado em Educação) - Universidade Federal da Paraíba.

SPODEK, Bernard; BROWN, Patricia Clark. Alternativas Curriculares na Educação da Infância: uma perspectiva histórica. In: FORMOSINHO, Júlia Oliveira (Org.). Modelos curriculares para a educação de infância. Porto: Porto, 1996. 